\title{
Self-medication for infants with colic in Lagos, Nigeria
} Kazeem A Oshikoya*1,2,3, Idowu O Senbanjo ${ }^{2}$ and Olisamedua F Njokanma ${ }^{2}$

Address: ${ }^{1}$ Pharmacology Department, Lagos State University College of Medicine, P.M.B 21266, Ikeja, Lagos, Nigeria, ${ }^{2}$ Paediatrics and Child Health, Lagos State University Teaching Hospital, Ikeja, Lagos, Nigeria and ${ }^{3}$ Academic Division of Child Health, University of Nottingham, The Medical School, Derbyshire Children's Hospital, Uttoxeter Road, Derby, DE22 3DT, UK

Email: Kazeem A Oshikoya* - med_modhospital@yahoo.com; Idowu O Senbanjo - senbanjo001@yahoo.com;

Olisamedua F Njokanma - faconj@yahoo.com

* Corresponding author

Published: 4 February 2009

BMC Pediatrics 2009, 9:9 doi:10.1 I86/147|-2431-9-9
Received: 25 July 2008

Accepted: 4 February 2009

This article is available from: http://www.biomedcentral.com/I47I-243I/9/9

(c) 2009 Oshikoya et al; licensee BioMed Central Ltd.

This is an Open Access article distributed under the terms of the Creative Commons Attribution License (http://creativecommons.org/licenses/by/2.0), which permits unrestricted use, distribution, and reproduction in any medium, provided the original work is properly cited.

\begin{abstract}
Background: Infantile colic is a self-limiting condition that is distributed worldwide. It is often misdiagnosed as an organic disease for which an infant is admitted to the hospital. Many studies have described the aetiopathogenesis, pharmacologic and non-pharmacologic management of colic but none has evaluated self-medication for infants with colic. The aim of this study was therefore to determine the knowledge of Nigerian mothers about colic, their home-based management, extent of self-medication for the infants with colic and the types of medicines involved.
\end{abstract}

Methods: It is a prospective study conducted at the vaccination clinics of 20 primary health care centres, each from different Local Government Areas in Lagos, Nigeria. Eight hundred mothers that brought their infants for vaccination between April and September, 2006 were interviewed with open-and close-ended questionnaire.

Results: Six hundred and eighty three (85.4\%) mothers claimed they had a good knowledge of colic. Incessant and excessive cry was the main clinical feature of colic identified by $430(62.9 \%)$ mothers. Three hundred and seventy eight $(67.7 \%)$ infants were treated by self-medication, 157 (28.1\%) sought medical intervention and 17 (3.1\%) were treated at a traditional birth attendant home. Herbal medicines constituted $5 \mathrm{I} .8 \%$ of the self-medicated medicines, of which $48(26.2 \%)$ were "Ororo Ogiri". Nospamin ${ }^{\circledR}(49.5 \%)$ and Gripe water ${ }^{\circledR}(43.0 \%)$ were the two frequently prescribed and self-medicated medicines for infants with colic.

Conclusion: Nigerian mothers are deficient in their knowledge of colic. Self-medication was the most frequently used home-based intervention. Health education would appear necessary to improve parental management of this self-limiting condition.

\section{Background}

Infantile colic is a syndrome characterised by excessive, unexplained paroxysmal crying in an otherwise healthy baby [1-3]. The crying typically starts in the first few weeks of life and spontaneously resolves between 3-5 months [1-4]. Excessive crying is defined as crying that lasts more than three hours per day and more than three days per week for at least 3 weeks [2-5]. The cry has been typically described as a high-pitched scream, occurring mainly in the late afternoon or evening but may occur at any time. Characteristically, the infants' knees are drawn up to the abdomen, face is flushed, fists are clenched, flatus is 
expelled, the facies is "pained" and there is minimal response to attempts at soothing [1].

Colic affects $5 \%$ to $25 \%$ of infants throughout the world, depending on the study design, definition of colic and method of data collection [6,7]. It is derived from the Greek word colon, reflecting that it involved some bowel disturbances [7]. Previous studies have attributed colic to painful intestinal contractions, lactose intolerance, presence of gas in the gut, and parental misinterpretation of normal crying [2]. However, in recent times, it was hypothesised that infantile colic may have a medical or behavioural cause [3]. The medical hypotheses include food hypersensitivity or allergy $[8,9]$ and immaturity of gut function or gut dymotility $[3,10,11]$. The behavioural hypotheses include inadequate maternal-infant interaction [12], maternal anxiety [5] and difficult infant temperament [13]. Other recent hypotheses that are being investigated are hormone alterations $[11,14]$ and maternal smoking [3]. The role of gut microflora in the aetiopathogenesis of colic has been reported too [15-17]. The linking of colic to organic causes has changed its management interventions which include the use of wider range of pharmacological agents such as antispasmodic $[18,19]$, defoaming agents [3], gut hormone antagonists [11,14], herbal medicines [19-21] and probiotics [6,22].

Both behavioural and pharmacological interventions have been studied over the years in the management of colic and have demonstrated a significant improvement in the symptoms $[3,13,23]$. However, only a few of these interventions have been confirmed by randomised clinical trials [3]. Infantile colic usually has a favourable course and outcome; even without treatment. Most infants are free of the symptoms by the age of 4-5 months [3]. However, most parents are faced with tremendous stress and are unlikely to tolerate the stress until the symptoms completely disappear without medical intervention; therefore medical help is either sought [24-26] or self- medication practiced by the parents [27]. Most doctors and nurses believe something has to be done to assist parents of infants with colic because of the stress $[3,23]$. The role of physicians in the management of colic is to exclude serious organic causes of inconsolable cry and offer a balanced advice on treatments [28]. At present, behavioural management, supportive counselling and parental reassurance are the mainstays of treatment $[1,13,28]$. Other non-pharmacological interventions such as feeding changes $[29,30]$ and oral administration of sucrose solution [23] have been found useful in the management of colic.

The use of herbal medicines for common childhood illnesses has been reported in Nigeria $[31,32]$ but its use in the management of colic has not been explored. About
$85 \%$ of Nigerians are known to use and consult traditional medicine for healthcare, social and psychological benefits because of poverty and disillusionment with conventional medical care [33]. Only a few of the herbal medicines in circulation in Nigeria are registered by the National Agency for Food and Drug Agency and Control (NAFDAC) [34]. The importance of traditional medicine in Nigerian healthcare has been recognised by the national government who set up a high profile committee to develop, promote and commercialise traditional medicine products [35]. Efforts have also been made by the government to preserve indigenous Nigerian medical knowledge by boosting research into traditional medicine [35].

Self-medication is a global problem and is associated with adverse drug reactions [36], treatment failure [37] and resistance to antibiotics and antimalarials [38]. A 47.6\% prevalence of self-medication has been reported among infants in Lagos, Nigeria. Abdominal pains, constipation, fever and cough are the most common symptoms of infants that are frequently treated by self-medication in Nigeria $[31,32]$. Previous studies that evaluated self-medication among infants in developing countries did not evaluate infants with colic $[30,31,39]$. In 1973, Buchanan first reported self-medication for colic in an urban black population in South Africa [27]. A major limitation of the study was that self-medication was assessed in a general population predominated by adults. Since pharmacological intervention remains one of the management strategies of colic, it is appropriate to assess the extent of selfmedication in the management of this condition. This study was therefore aimed to determine the knowledge of Nigerian mothers about colic, their home-based management, extent of self-medication for infants with colic and the types of medicines involved.

\section{Methods}

Lagos is the smallest state but the most populous city in Nigeria with an estimated population of about 15 million inhabitants as of 1991 national census. It is divided into five divisions and twenty Local Government Areas (LGAs). There is at least a minimum of three Primary Health Care (PHC) centres in each LGA. One PHC was selected randomly from each LGA, thus a total of twenty PHC centres were used for data collection.

The study was conducted prospectively between April and September, 2006. Mothers who brought their infants for vaccination were randomly selected (40 from each PHC) and interviewed with a structured questionnaire. A total of 800 mothers were interviewed. The questionnaire was designed to obtain the demographics of both the mothers and their infants, and to assess their knowledge about infantile colic and how it was managed. Among those 
mothers that managed their infant's colic at home, the types of intervention used were sought. If pharmacological intervention was used, the types of medicine used and their sources were also sought. Similarly, among those infants managed for colic in hospitals, information on the medical advice given to the mothers and the medicines prescribed were also obtained with the questionnaire. The questionnaire was both open- and close-ended, developed from literature review on infantile colic [1-20] and from the opinion of mothers interviewed in a pilot study. In addition to literature review, previous studies that evaluated self-medication in Nigerian infants [31-33] and the opinion of community pharmacies and traditional herbal medicine practitioners were used to develop part of the questionnaire that focused on home management of colic. The interview was conducted by matrons in charge of the PHC, who have been trained for the study. The interview lasted about 30 minutes and was conducted in a consulting room. A mother was interviewed at a time to allow privacy. Only the mothers with a healthy infant and consented to participate in the study were interviewed.

A pilot study was carried out at one of the excluded PHC centres to enable us correct all the identified problems in the questionnaire. Most of the mothers suggested additional medicines and herbal medicine products that were not included on the questionnaire which they have used to treat infantile colic.

The data collected were analysed using SPSS version 13. Statistical analysis was by Fischer exact and Chi-square tests at a significant value of $P<0.05$.

\section{Results}

Demography of the mothers and their infants

Most of the mothers (36.1\%) were in the age group 21-25 years (range 15 to 40 years). The mothers' level of education ranged from illiteracy $(2.5 \%)$ to university education (25.0\%). Two hundred and twenty (36.3\%) mothers were traders, $212(26.5 \%)$ professionals and others were unemployed, students or artisans. The age of the infants ranged from one day to12 months. A majority of the infants $(51.63 \%)$ were in the age group of one to 6 months. Their mean age was $4.9 \pm 3.3$ months. Four hundred and thirteen $(51.6 \%)$ of the infants were female and 387 (48.4\%) were male. Seven hundred and twenty (90.0\%) infants were exclusively breastfed, 63 (7.9\%) were partly breast fed and partly fed with formula feed, and 17 (2.1\%) were exclusively fed with formula feed.

\section{Knowledge of mothers about infantile colic}

Six hundred and eighty three (85.4\%) mothers claimed they had a good knowledge of colic. A majority of the mothers (59.6\%) were informed about colic by their parents, grand parents and personal experience from their previous children with colic. Other sources of information about colic are summarised in Table 1.

The features of colic, as perceived by the mothers, are presented in Table 2. Only incessant and excessive cry was correctly identified by 430 (62.9\%) mothers as a main feature of infantile colic. There was a significant increase in the proportion of mothers with higher education who correctly identified incessant and excessive cry as a main feature of colic when compared with mothers with secondary and primary education $(P=0.023)$. However,

Table I: Sources of information about infantile colic

\begin{tabular}{|c|c|c|}
\hline Source & $\begin{array}{l}\text { Frequency } \\
(\mathrm{n}=683)\end{array}$ & $\begin{array}{c}\text { Percentage } \\
\text { (\%) }\end{array}$ \\
\hline Parents/grand parents & 190 & 27.8 \\
\hline Experience from previous child/children & 163 & 23.9 \\
\hline Experience from previous child/children + Parents/grand parents & 61 & 8.9 \\
\hline In-laws & 50 & 7.3 \\
\hline Parents/grand parents + in-laws & 41 & 6.0 \\
\hline Friends & 23 & 3.4 \\
\hline Traditional birth attendants & 22 & 3.2 \\
\hline Friends + parents/grand parents & 20 & 2.9 \\
\hline Experience from previous child/children + Friends & 19 & 2.8 \\
\hline Hospital & 15 & 2.2 \\
\hline Nurse & 12 & 1.8 \\
\hline Health centre & 11 & 1.6 \\
\hline Neighbours & 11 & 1.6 \\
\hline Friends + relations + parents/grand parents & 10 & 1.5 \\
\hline Friends + relations & 9 & 1.3 \\
\hline Reading from books/TV/Radio programmes & 9 & 1.3 \\
\hline Relations & 9 & 1.3 \\
\hline Internet & 8 & 1.2 \\
\hline
\end{tabular}


Table 2: Signs and symptoms of colic identified by the mothers

\begin{tabular}{lcc}
\hline Features & $\begin{array}{l}\text { Yes } \\
(\%)\end{array}$ & $\begin{array}{l}\text { No } \\
(\%)\end{array}$ \\
\hline $\begin{array}{ll}\text { Correct features } \\
\text { Incessant and excessive cry }\end{array}$ & \\
Irritability & 62.6 & 37.4 \\
Passage of flatus & 21.9 & 78.1 \\
Intermittent cry & 17.6 & 82.4 \\
Healthy state of the infant & 13.2 & 86.8 \\
Insomnia & 8.8 & 91.2 \\
Incorrect features & 4.4 & 95.6 \\
Refusal of feeds & & \\
Inconsolable cry & 36.6 & 63.4 \\
Abdominal pains & 29.3 & 70.7 \\
Fever & 17.6 & 82.4 \\
All day cry & 7.3 & 92.7 \\
Passage of loose stool & 7.2 & 92.8 \\
& 3.1 & 96.9 \\
\hline
\end{tabular}

$\mathrm{N}=683$ (total number of mothers that were knowledgeable of infantile coilc), $n=$ number of mothers that responded to each of the questions, \% response $=\mathrm{n} / \mathrm{N}$

mothers between $30-40$ years and those younger did not differ significantly in their knowledge of incessant and excessive cry as a main feature of colic $(P=0.062)$. Refusal of feeds, inconsolable cry and abdominal pains were the three most frequent incorrect features of colic wrongly identified as correct features.

Infantile colic related cry was correctly defined according to Wessel et al criteria by $423(61.9 \%)$ mothers. Five hundred and sixty five $(82.7 \%)$ mothers identified colic onset as one week of life, 417 (61.1\%) mothers believed colic could last up to 5 months of life and 143 (20.9\%) mothers believed that colic has a cause. Highly educated mothers were able to associate colic to a cause more than mothers with secondary and primary education $(101 / 296$ vs $42 / 367, P<0.05)$, but the proportion of mothers between 30-40 years did not differ significantly from younger mothers that understood that colic has a cause $(P$ $=0.058$ ). Table 3 shows the list of the causes of colic as perceived by the mothers. Abdominal cramps with hyperperistalsis $(60,39.8 \%)$ were the most frequently identified correct cause of colic. Contrarily, 34 (23.8\%) mothers wrongly identified worm, breast milk allergy and brain problem as causes of colic.

Of the 683 mothers who claimed good knowledge of colic, $201(36 \%)$ responded that their infants were currently experiencing colic. Colic was experienced at a mean age of $17.4 \pm 1.0$ days (range of 4 days to 2 months). One hundred and seventy $(42.5 \%)$ infants with colic have older siblings that had experienced colic. The older siblings experienced colic at a mean age of $22.72 \pm 1.18$ days (range 4 days to 3 months) which was significantly higher
Table 3: Perceived causes of infantile colic

\begin{tabular}{lcc}
\hline Causes & $\begin{array}{c}\text { Yes } \\
(\%)\end{array}$ & $\begin{array}{c}\text { No } \\
(\%)\end{array}$ \\
\hline Hypothesised (correct) causes & & \\
Abdominal cramps with hyper-peristalsis & 39.8 & 60.2 \\
Presence of gas in the intestine & 16.1 & 83.9 \\
Gastroesophageal reflux & 11.9 & 88.1 \\
Allergy to formula milk & 4.2 & 95.8 \\
Attachment to the mother & 4.2 & 95.8 \\
Non-hypothesised (incorrect) causes & & \\
Worm & 11.9 & 88.1 \\
Allergy to breast milk & 7.7 & 92.3 \\
Brain problem & 4.2 & 95.8 \\
\hline
\end{tabular}

$\mathrm{N}=143$ (total number of mothers that perceived colic has a cause), $\mathrm{n}$ $=$ number of mothers that responded to each of the questions, $\%$ response $=n / N$

than the mean age $(17.4 \pm 1.0$ days $)$ of the current infants with colic $(\mathrm{P}<0.05)$.

\section{Mothers' management of colic}

Of the 558 infants that experienced colic, 378 (67.7\%) were treated at home by their mothers, 157 (28.1\%) sought medical intervention in a hospital, 17 (3.1\%) were treated by traditional herbal medicine practitioners; the remaining six were not given any treatment. There were no significant differences in the proportion of mothers with higher education and those with secondary and primary education, mothers between 30-40 years and those younger who employed home-based and hospital-based interventions, respectively, in the management of their infants' colic $(P>0.05)$. However, mothers who were professionals tend to use home-based interventions more than those who were traders $(P=0.012)$ for colic management. Contrarily, mothers who were traders sought hospital- based interventions more than those who were professionals $(P=0.023)$.

\section{Self-medication}

Of the 378 infants treated at home by the mothers, 353 (93.4\%) were treated by self-medication. Levels of education and age of the mothers appear not to have a significant influence on the extent of self-medication for infants with colic $(P=0.073$ and $P=0.055$, respectively). Table 4 shows the list of self-medicated medicines used to treat infantile colic by mothers. Herbal medicines were the most frequently used medicines $(51.8 \%)$, of which 48 $(26.2 \%)$ were "Ororo Ogiri"; $22(12.1 \%)$ were a mixture of Allium asalonicum L. (Onion) leaves,Syzygium aromaticum L. seeds and Parinari spp. seeds soaked in water; 21 $(11.5 \%)$ were Allium asalonicum L. leaves only soaked in water; $13(7.1 \%)$ were a mixture of naphthalene tablets, Allium sativum L.(Garlic) and Allium asalonicum L. leaves soaked in water; and $11(6.0 \%)$ were Allium sativum $L$. only soaked in water. The components of the remaining 
Table 4: List of self-medicated medicines used to treat infantile colic

\begin{tabular}{lcc}
\hline Drugs & $\begin{array}{c}\text { Frequency } \\
(\mathrm{n}=353)\end{array}$ & $\begin{array}{c}\text { Percentage } \\
(\%)\end{array}$ \\
\hline Herbal medicines $_{\text {Nospamin }}^{\circledR}$ & 183 & 51.8 \\
Gripe water $^{\circledR}$ & 125 & 35.4 \\
Bonababe $^{\circledR}$ & 106 & 30.0 \\
Piccan $^{\circledR}$ & 19 & 5.4 \\
Kidcare $^{\circledR}$ & 7 & 2.0 \\
Teething powder $^{\circledR}$ & 4 & 1.1 \\
'Gbomoro $^{\circledR}$ & 4 & 1.1 \\
Paracetamol $_{\text {Ascorbic acid }}$ & 3 & 0.8 \\
Ampicillin/cloxacillin & 3 & 0.8 \\
& 3 & 0.8 \\
\hline
\end{tabular}

Multiple dugs used was observed here with an average drug used per patient of I.3

Nospamin ${ }^{\circledR}$ : Homatropine methylbromide (an anticholinergic).

Gripe water ${ }^{\circledR}$ : Contains Terpeneless dill seed oil, sodium bicarbonate, ginger tincture and alcohol $0.22 \mathrm{I} \mathrm{ml}$.

Bonababe ${ }^{\circledR}$ : Contains paracetamol, diphenhydramine and concentrated dill water.

Piccan ${ }^{\circledR}$ : Contains paracetamol and diphenhydramine

Kidcare $^{\circledR}$ : contains chloroquine.

Teething powder ${ }^{\circledR}$ : Contains tincture of matricaria and lactose.

'Gbomoro' ${ }^{\circledR}$ : Contains chloroquine.

68 herbal medicines could not be ascertained by the mothers.

The remaining self-medicated medicines were over-the counter medicines, except homatropine methylbromide $\left[\right.$ Nospamin $\left.^{\circledast}\right](125,35.4 \%)$ and ampicillin/cloxacillin (3). Most of the medicines were used either in combination with herbal medicines or in combination with other medicines.

\section{Chiropractic intervention}

In addition to parental self-medication, 120 (31.8\%) infants were managed by massaging their abdomen with anointing oil or herbal mixtures. Mothers placing hands on the abdomen of their infants with colic or laying the infants on their abdomen (56.4\%) and applying hot water bottle to the colicky abdomen $(21.8 \%)$ were the other chiropractic interventions practised by the mothers.

\section{Psychosocial intervention}

One or more psychosocial interventions were adopted by $133(35.2 \%)$ mothers, either alone or in combination with self-medication, in the management of colic. The psychosocial interventions included early response to the child while crying (24.8\%), giving a pacifier to suck (18.1\%), giving a gentle soothing motion $(10.5 \%)$, avoidance of over-stimulation $(9.8 \%)$ and carrying the infant in a carrier or a stroller $(9.0 \%)$ to move around.

\section{Combined non-pharmacological interventions}

Thirty of the 35 infants with colic that were managed at home without self-medication were managed psychosocially and by massaging their abdomen with anointing oil or herbal mixtures. The rest were managed either psychosocially or by giving only abdominal massage.

\section{Hospital-based interventions for infantile colic}

Amongst the 157 mothers that sought medical treatment for their infants' colic, 77 (49.0\%) were treated only once and $68(43.3 \%)$ were treated twice by doctors. Most of these infants $(59.3 \%)$ were prescribed medicines. Thirty nine $(24.8 \%)$ mothers were counselled about the cause and course of colic and the rest of the infants (15.9\%) were investigated for the cause of abdominal pain. Nospamin $^{\circledast}(49.5 \%)$, Gripe water ${ }^{\circledast}(43.0 \%)$, Piccan ${ }^{\circledast}$ (12.9\%), Erythromycin (10.8\%), and $\operatorname{Abidec}^{\circledast}(9.7 \%)$ were the medicines prescribed by doctors, either alone or in combination, for the treatment of colic.

\section{Discussion}

Colic is a problem of infants with a high incidence reported worldwide $[6,7]$. An incidence rate of $36 \%$ was obtained in this study. This rate is slightly higher than the $5 \%$ to $30 \%$ previously reported in some studies $[6,7,40$ 42 ] but falls in-between the $35 \%$ to $40 \%$ reported in other studies $[43,44]$. The differences in the incidence rates may be due to variations in the definition of colic and of differences in study design, method of data collection and population size between different studies $[6,7]$. In the present study, only the mothers that brought their infants for vaccination were interviewed, therefore, the reported incidence rate of colic may not represent the true incidence in Lagos.

Most of the mothers $(85.4 \%)$ claimed that they were knowledgeable of the cause and course of colic. This was demonstrated by the ability of $82.7 \%$ of the mothers to correctly identify onset of colic as one to two weeks of life and $61.1 \%$ of the mothers being able to identify its complete disappearance by 5 months of life. The high level of education of the mothers may explain their good knowledge of colic. Colic has been reported to be more common in the first-born child and infants whose siblings had suffered colic [40]. Successful management of colic by grand mothers and mothers in their previous infants with colic would have earned them the knowledge and experience of colic. Therefore information from grandparents and experienced mothers is likely to be reliable in the management of colic. Unfortunately, the most reliable sources of information about colic (hospital, health centres, nurses, TV/ radio and internet) were not sought by the majority of the mothers (Table 1). Therefore much publicity about colic, targeted at mothers, would appear necessary in Lagos. This can be achieved by health education talk in the vacci- 
nation and other paediatric clinics, and using posters and TV/radio jingles.

Over $60 \%$ of the mothers were able to define colic according to Wessel's criteria [45]. Incessant and excessive cry has been reported as a main feature of colic [2] and this was correctly identified by $62.9 \%$ of the mothers. The fact that a significant proportion of these mothers were highly educated shows that health education about colic at the vaccination clinic would likely be embraced by the mothers. However, other associated symptoms of colic that were not correctly identified by the mothers and the incorrect symptoms that were considered features of colic (Table 2) may lead to delay in seeking hospital care for serious illnesses that may mimic colic in infants. The incorrect features identified by the mothers such as refusal of feeds, inconsolable cry, abdominal pain, crying all day, fever and passage of loose stool are presenting features of malaria, sepsis or other life-threatening infectious diseases in infants [46]. Delay in their treatment could result in early infant morbidity and mortality.

Home-based management of colic was a common practice by the mothers. This finding was supported by the $67.7 \%$ of the mothers who treated their infants with colic without consulting with doctors. Parent reassurance, empathy, support and asking the mothers to take time-out when their infants were crying are home-based nursing interventions used to reduce parenting stress [13]. Other studies have shown that abdominal massage [23], administration of sucrose solution [23], and use of herbal tea $[18,19]$ or hydrolysed formula [17] were equally very effective in reducing the duration of crying in infants with colic. These interventions are easy to apply and practicable at home by families without necessarily seeking the help of a doctor. However, parents must be able to properly identify symptoms of colic before adopting home-based interventions.

Self-medication and use of herbal medicines were the most practiced home-based interventions in this study unlike the non-pharmacological interventions recommended in other studies $[13,23]$. The $51.8 \%$ of mothers using home-based interventions were involved in the use of herbal medicines for their infants with colic. This high prevalence of herbal medicine use may be explained by the recognition given to traditional medicine in Nigerian healthcare by the Federal Government [35]. The use of herbal tea in the treatment of infantile colic has been reported in the developed countries $[13,19,20]$ but the herbal medicines used by the infants in this study are quite different. Lagos is a metropolitan area, comprising of people from different tribes and cultures, therefore the population of mothers that participated in this study represent different cultures and tribes in Nigeria. The use of herbal medicines for infants with colic may therefore be considered a common practice among mothers of different culture and tribes in Nigeria but the types of herbal medicine used may likely differ. "Ororo Ogiri" (26.2\%) was the mostly used herbal medicine. It is derived from putrefied Cucumeropsis mannii (melon) seeds which are used as a local food seasoning amongst the Yoruba tribe in Nigeria. When dissolved in water and drank by adults, it relieves indigestion by causing excessive farting and flatulence. Its use in the treatment of infantile colic was based on the hypothesis that it removes the excess intraluminal gas in the infant by causing flatulence. The safety of the herbal medicines in infants would necessitate their pharmacological and toxicological studies. We have earlier reported hepatic encephalopathy and death from the use of herbal preparations containing naphthalene tablets [36], therefore the $7.1 \%$ infants that were treated with a mixture of naphthalene tablets, Allium sativum $L$. and Allium asalonicum $L$. leaves soaked in water are at risk of such severe adverse reactions.

Infantile colic is self-limiting and has a favourable clinical course without treatment $[2,47,48]$. Although serious somatic problems are absent in most cases, yet doctors and nurses provide both medical and behavioural interventions to allay the stress posed by colic on the parents [47]. It is therefore not surprising to see $59.3 \%$ of the infants that were seen by doctors for colic prescribed medicines. It is interesting to know that $24.8 \%$ mothers were counselled about the cause and course of colic and 15.9\% infants investigated for the cause of abdominal pain. Even though these percentages were low, they indicate that rational drug use can be achieved in the management of colic in Lagos. Nospamin ${ }^{\circledast}$ is homatroprine methylbromide (an anticholinergic) which was prescribed to $49.5 \%$ infants and used in $35.4 \%$ infants without prescription. The use of anticholinergics for infantile colic as prescribed and non-prescribed medicines has been reported $[18,42,49]$. Evidence-based medicine has shown a clear benefit of these drugs in the treatment of excessive crying in infants [47]. However, their reported side effects in infants are of great concern [50] which may limit their use. There is much anecdotal evidence extolling the benefit of gripe water $^{\circledast}$ for colic but no formal evaluation of this medicine has been undertaken [51]. Gripe water ${ }^{\circledR}$ has been in use for treating colic over 100 years ago [51]. This may explain the $43.0 \%$ doctors that prescribed the medicine and the $30.0 \%$ of mothers that were involved in its selfmedication. It has been hypothesised that the alcohol content of gripe water ${ }^{\circledast}$ provides a soothing effect [52], the bicarbonate provides a neutralizing effect to the gastric acid [51], and the carminative in the plant extract causes the soothing of the infant in the presence of excess gas in the lumen that may cause pain [53]. Allium sativum L. has been reported to produce flatulence in man [54] and Syzy- 
gium aromaticum L. is known to contain clove-oil as one of its constituents which is used as carminative [54]. The use of fennel oil similar to the clove-oil has been reported to be helpful in colic management. These treatments are however not entirely harmless [55], therefore proper dose has to be scientifically determined.

Laying the infant on the abdomen (56.4\%), early response to the child while crying $(24.8 \%)$, giving the infant a gentle soothing motion (10.5\%) and avoidance of over-stimulation (9.8\%) observed in this study are acceptable psychosocial methods of managing infantile colic which have been widely reported $[1,22,47,56,57]$. However, applying hot water bottle to the abdomen of the infant, as practiced by $21.8 \%$ mothers, has been reported to relieve rectal spasm to aid easier passage of flatus [58]. Although parents must be cautioned about the use of this method as they stand the risk of causing burn to the infants' abdomen.

The findings from this study may not be comparable to the general population since only a particular population of mothers were studied. The findings may be different if mothers attending other paediatric clinics were studied. This is however one of the limitations of the study.

\section{Conclusion}

Nigerian mothers are deficient in their knowledge of cause and course of infantile colic. Self-medication was the most frequently used home-based interventions for infantile colic and was predominated by traditional herbal medicines. Nigerian mothers would need to be educated about colic through health education at paediatric and vaccination clinics, public health campaign and interdisciplinary team approach. Efficacy and toxicity of the traditional herbal medicines need to be established scientifically for their safe use for children. Government should strengthen the policy on sales and use of prescribed medicines in children without prescription so as to promote rational use of medicine in infants with colic.

\section{Abbreviations}

NAFDAC: National Agency for Food and Drug Agency and Control; LGA: Local Government Authority; PHC: Primary Health Care.

\section{Competing interests}

The authors declare that they have no competing interests.

\section{Authors' contributions}

KAO conceived the study, designed the study and questionnaire, analysed the data, and drafted the manuscript. IOS critically reviewed the statistical analysis and participated in drafting the manuscript. FON participated in the design of the questionnaire and critically reviewed the manuscript.

\section{Acknowledgements}

We acknowledge the efforts of Mrs E.O Ayorinde and Mrs J.A. Bello of the Pharmacology Department, Lagos State University College of Medicine, Ikeja, Lagos, for assisting to organise the mothers for the interview. We also appreciate the matrons in charge of the PHC centres where the study interview was conducted.

\section{References}

I. Balon AJ: Management of infantile colic. Am Fam Physician 1997, 55:235-242.

2. Lucassen PL, Assendelft WJ, Gubbels JW, van Eijk JT, van Geldrop WJ, Neven AK: Effectiveness of treatments for infantile colic: systematic review. $B M$ J 1998, 3 I6:1563-1569.

3. Savino F: Focus on infantile colic. Acta Paediatr 2007, 96:1259-1264.

4. Barr RG: Colic and crying syndromes in infants. Paediatrics |99|, 84:450-455.

5. Leung AK, Lemay JF: Infantile colic: a review. J R Soc Health 2004, 124:162-166.

6. Lucassen PLBJ, Assendelft WJ, van Eijk JT, Gubbels JW, Douwes AC, van Geldrop WJ: Systematic review of the occurrence of infantile colic in the community. Arch Dis Child 200I, 84:398-403.

7. Clifford TJ, Campbell MK, Speechley KN, Gorodzinsky F: Sequence of infant colic: evidence of transient infant distress and absence of lasting effects on maternal mental health. Arch Pediatr Adolesc Med 2002, I 56: I I 83-I I 88.

8. Hill DJ, Hosking CS: Infantile colic and food hypersensivity. J Pediatr Gastroenterol Nutr 2000, 30:S67-76.

9. Kallionmaki M, Lappala P, Korvenranta H, Kero P, Isolauri E: Extent of fussing and colic type crying preceding atopic disease. Arch Dis Child 200I, 84:349-350.

10. Weissbluth M, Christofell KK, Davis AT: Treatment of infantile colic with dicyclomine hydrochloride. J Pediatr 1984, 104:95I-955.

II. Savino F, Grassino EC, Guidi C, Oggero R, Silvestro L, Miniero R: Ghrelin and motilin concentration in colicky infants. Acta Paediatr 2006, 95:738-74I.

12. Lucas A, St James-Roberts I: Crying, fussing and colic behaviour in breast-and bottle-fed infants. Early Hum Dev 1998, 53:9-18.

13. Keefe MR, Kajrlsen KA, Lobo ML, Kotzer AM, Dudley WN: Reducing parenting stress in families with irritable infants. Nurs Res 2006, 55: 198-205.

14. Lothe L, Ivarsson A, Lindberg T: Motilin, vasoactive intestinal peptide and gastrin in infantile colic. Acta Paediatr Scand 1987, 76:316-320.

15. Lehtonen L, Korvenranta $\mathrm{H}$, Eerola : Intestinal microflora in colicky infants: bacterial cultures and gas-liquid chromatography. J Pediatr Gastroenterol Nutr 1994, 19:310-314.

16. Savino F, Cresi F, Pautasso S, Palumeri E, Tullio V, Roana J, et al: Intestinal microflora in breastfed colicky and non-colicky infants. Acta Paediatr 2004, 93:825-829.

17. Savino F, Bailo E, Oggero R, Tullio V, Roana J, Carlone N, et al.: Bacterial counts of intestinal Lactobacillus species in infants with colic. Pediatr Allergy Immunol 2005, 16:72-75.

18. Savino F, Brondello C, Cresi F, Oggero R, Silvestro L: Cimetropium bromide in the treatment of crisis in infant colic. J Pediatr Gastroenterol Nutr 2002, 34:417-4I9.

19. Weizman Z, Alkrinawi S, Goldfarb D, Bitran C: Efficacy of herbal tea preparation in infant colic. J Pediatr 1993, I 22:650-652.

20. Savino F, Cresi F, Castagno E, Silvestro L, Oggero R: A randomised double-blind placebo controlled trial of a standardized extract of Matricariae recutita, Foeniculum vulgare and Melissa officinalis (ColiMil ${ }^{\circledR}$ ) in the treatment of breastfed colicky infants. Phytother Res 2005, 19:335-340.

21. Wade S, Kilgour T: Clinical review. BMJ 200I, 323:437-440.

22. Garrison MM, Christakis DA: Early childhood: colic, child development, and poisoning prevention. A systematic review of treatments for infant colic. Paediatrics 2000, 106:184-190.

23. Arikan D, Alp H, Gozum S, Orbak Z, Cifci EK: Effectiveness of massage, sucrose solution, herbal tea or hydrolysed formula 
in the treatment of infantile colic. J Clin Nurs 2008, 17:|754-|76|.

24. Alvarez M, James-Roberts I: Infant fussing and crying patterns in the first year in an urban community in Denmark. Acta Paediatr 1996, 85:463-466.

25. St James-Roberts I, Halil AT: Infant crying patterns in the first year: normal community and clinical findings. J Child Psychol Psychiatry 1991, 32:951-968.

26. Forsyth BW, Leventhal JM, McCarthy PL: Mothers' perceptions of problems of feeding and crying behaviour. Am J Dis Child I985, 139:269-272.

27. Buchanan N: Self-medication in a developing country. S Afr Med J 1979, 56:609-6II.

28. Garg P: Infantile colic-unfolded. Indian J Pediatr 2004, 7 I:903-906.

29. Hill DJ, Hudson IL, Sheffield LS, Shelton MJ, Menahem S, Hosking CS: A low allergen diet is a significant intervention in infantile colic: results of a community-based study. J Allergy Clin Immunol 1995, 96:886-892.

30. Forsyth BW: Colic and the effect of changing formulas: a doubleblind, multiple-crossover study. J Pediatr 1989, I I 5:52 |-526.

31. Oshikoya KA, Njokanma OF, Bello JA, Ayorinde EO: The use of prescribed and non-prescribed drugs in infants in Lagos, Nigeria. IMed Sci 2008, 8: III-II7.

32. Oshikoya KA, Njokanma OF, Bello JA, Ayorinde EO: Family selfmedication for children in an urban area of Nigeria. Paediatr Perinat Drug Ther 2007, 8: | 24-130.

33. Adesina SK: Traditional medical care in Nigeria. [http:// www.onlinenigeria.com/links/LinksReadPrint.asp?blurb=574]

34. NAFDAC NIGERIA: Journey: some administrative guidelines. [http://www.nafdacnigera.org/journey.html].

35. Adelaja A: Nigeria boosts research into traditional medicine. 2006 [http://www.scidev.net/en/news/nigeria-boosts-research-intotraditional-medicine.html]. Science and Development Network: news, views and information about science and technology and the development world

36. Oshikoya KA, Njokanma OF, Chukwura HA, Ojo OI: Adverse drug reactions in Nigerian children. Paed Perinat Dug Ther 2007, 8:8I-88.

37. Sihavong A, Lundborg CS, Syhakhang L, Akkhavong K, Tomson G Wahlsstrom R: Antimicrobial self medication for reproductive tract infections in two provinces in Lao People's Democratic Republic. Sexually Transmitted Infections 2006, 82: I82-186.

38. Awad A, Eltayeb I, Matowe L, Thalib L: Self-medication with antibiotics and antimalarials in the community of Khartoun State, Sudan. J Pharm Pharm Sci 2005, 8(2):326-33I.

39. Zaki R, Abdel-Fattah M, Bassili A, Arafa M, Bedwani R: The use of medication in infants in Alexandria, Egypt. Eastern Mediter Health J 1999, 5(2):320-327.

40. Becker N, Lombardi P, Sidoti E, Katkin LS: Mylicon drops in the treatment of infant colic. Clin Ther 1998, I 0(4):40I-405.

41. Clyne PS, Kulczycki A: Human breast milk contains bovine IgG: Relationship to infantile colic? Pediatrics 1991, 87:439-444.

42. Colon AR, Dipalma JS: Colic. Am Fam Physician 1989, 40:122-124.

43. Keefe MR: Irritable infant syndrome: Theoretical perspectives and practice implications. ANS Adv Nurs Sci 1988, 10(3):70-78.

44. Larson K, Ayllon T: The effects of contingent music and differential reinforcement on infantile colic. Behav Res Ther 1990, 28:119-125.

45. Wessel MA, Cobb JC, Jackson EB, Harris GS Jr, Detwiler AC: Parox ysmal fussing in infancy, sometimes called " colic". Pediatrics 1954, 14:421-435.

46. Oshikoya KA, Senbanjo IO: Fever in children: mothers' perception and their home management. Iranian J Pediatr 2008, 18:229-236.

47. Roberts DM, Ostapchuk M, O'brien JG: Infantile colic. Am Fam Physician 2004, 70:735-740.

48. Levitzky S, Cooper R: Infant colic syndrome- maternal fantasies of aggression and infanticide. Clin Pediatr 2000, 39:395-400.

49. Barr RG: Changing our understanding of infant colic. Arch Pediatr Adolesc Med 2002, I 56: I I72-I I74.

50. Physicians' Desk Reference. 50th edition. Montvale, NJ: Medical Economics Company; 1996:150I-I502.

51. Blumenthal I: The gripe water story. I $R$ Soc Med 2000, 93:172-174

52. Illingworth RS: Infantile colic revisited. Arch Dis Child 1985, 60:981-985.
53. Illingworth RS: 'Three months colic'. Arch Dis Child I954, 29:165-174.

54. Gill LS: Ethnomedical uses of plants in Nigeria. Benin City: University of Benin Press; 1992.

55. Alexandrovich I, Rakovitskaya O, Kolmo E, Sidorova T, Shushunov S: The effect of fennel (Foeniculum vulgare) seed oil emulsion in infant colic: a randomised, placebo controlled study. Altern Ther Health Med 2003, 9:58-61.

56. Lewinsohn P, Clarke GN, Rowhde P, Hops H, Seeley J: A course in coping: a cognitive-behavioural approach to treatment of adolescent depression. In psychosocial treatments for child and adolescent disorders Edited by: Hibbs ED, Jensen PS. Washington DC: American Psychiatric Association; 1997:109-135.

57. Wood AJ, Harrington RC, Moore A: Controlled trial of a brief cognitive behavioural intervention in adolescent patients with depressive disorders. J Child Psychol Psychiatry 1996, 37:737-746.

58. Adams LM, Davidson M: Present concepts of colic. Pediatr Ann 1987, 16(10):817-820.

\section{Pre-publication history}

The pre-publication history for this paper can be accessed here:

\section{http://www.biomedcentral.com/1471-2431/9/9/prepub}

Publish with BioMed Central and every scientist can read your work free of charge

"BioMed Central will be the most significant development for disseminating the results of biomedical research in our lifetime. "

Sir Paul Nurse, Cancer Research UK

Your research papers will be:

- available free of charge to the entire biomedical community

- peer reviewed and published immediately upon acceptance

- cited in PubMed and archived on PubMed Central

- yours - you keep the copyright 